\title{
INTRODUCCION AL UNIVERSO DE PARADIGMAS EN LA CONTABILIDAD DEL SIGLO XXI
}

DR. ERNESTO A. POLAR FALCÓN(*)

En los últimos tiempos, maestros y expositores de temas contables en el Perú están aplicando continuamente la palabra paradigma en sus clases y exposiciones, que merece conocer su significado y las razones por las cuales se está incorporando al lenguaje contable profesional y universitario.

Según el diccionario, paradigma significa modelo, teniendo también como sinónimos las palabras: ejemplo, forma, conformación, estructura, etc. Se puede entender entonces, desde el punto de vista contable, que un nuevo paradigma, en la contabilidad, es como un nuevo modelo, una nueva forma, una nueva conformación o una nueva estructura que nos hace pensar, meditar y analizar para aceptarlo como importante camino que conduce al conocimiento de los avances profesionales y tecnológicos de las ciencias contables en toda la gama de doctrinas y especialidades existentes actualmente.

Uno de estos paradigmas de la contabilidad es el que presenta el CP. Samuel Alberto Mantilla B. En su libro titulado CAPITAL INTELECTUAL - CONTABILIDAD DEL CONOCIMIENTO publicado en marzo de 1999 y que recién llegó a las manos del autor de este artículo en agosto del 2000, con motivo de asistir a un Seminario Interamericano de Contabilidad en Venezuela, auspiciado por la Asociación Interamericana de Contabilidad - AIC y la Federación de Colegios de Contadores Públicos de Venezuela. Dice en los tres primeros párrafos de su presentación lo siguiente:

\begin{abstract}
"Este libro presenta y analiza algunos documentos en relación con las temáticas de la Economía del Conocimiento, la Administración del Capital Intelectual y la Contabilidad del Conocimiento, que constituyen la temática de mayor avanzada a nivel empresarial y organizacional en el mundo.
\end{abstract}

Inicialmente hace algunos aportes en relación con los cambios, que ha tenido la contabilidad en épocas recientes. Se aparta sustancialmente de la idea de la contabilidad tradicional, centrada en el registro por partida doble y con fines fiscales, para introducir al lector en las temáticas más nuevas e importantes en el universo contable moderno. 
Posteriormente hace una síntesis, muy documentada, del estado actual de los estudios y prácticas del Capital Intelectual y la Contabilidad del Conocimiento, concentrándose en las más modernas metodologías de medición del desempeño que hoy se están empleando, con éxito, en diversas partes del orbe".

En la PRIMERA PARTE, bajo el título de "1. Contabilidad para la nueva centuria", anota lo siguiente:

"Aunque muchos contadores, enfrascados en venerar la aceptación generalizada quieren mantenerla monolítica y petrificada, porque en lugar de interpretar el negocio del cliente están más interesados en perpetuar una práctica que les dejó algunos dividendos o un estilo de interpretación dependiente de normas ya reemplazadas.

No obstante que algunos textos de contabilidad (usados en algunas universidades $(i)$ sigan reduciéndola a la sola teneduría de activos, pasivos y patrimonio, como si luego de Lucas Paciolo no se hubiera realizado ningún aporte innovador"

En la SEGUNDA PARTE, presenta el estudio realizado por el Comité de Contabilidad Financiera y Gerencial de la Federación Internacional de Contadores (IFAC por sus siglas en inglés), titulado: "Medición y Administración del Capital Intelectual : Una Introducción" que contiene los siguientes subtítulos:

- Trasfondo: La Economía del Conocimiento

- El Cambio Contable

- Capital Intelectual Definido

- Estructura Conceptual de la Administración del Capital Intelectual
- Tabla 1. Elementos del Capital Intelectual

- Capital Humano

- Capital Organizacional (Estructural)

- Análisis de la Cadena de Valor

- Capital del Cliente

- Medición del Capital Intelectual

- Informe Universal sobre el Capital Intelectual

- Centro en lo Financiero

- Tabla 2. Medidas para Administrar el Capital Intelectual

- Centro en el Cliente

- Centro en los Procesos

- Centro en Renovación y Desarrollo

- Centro en lo Humano

- Indicadores Comparativos

- Valor Intangible Calculado

- Conclusión

- Apéndice

- Referencias Bibliográficas

Este estudio, efectuado en 1998, consta de 48 párrafos llenos de inquietantes paradigmas y definiciones; por ejemplo, el párrafo 12 dice lo siguiente:

“12. La Society of Management Accountants of Canada (SMAC), en 1998, define activos intelectuales como sigue:

En términos de balance general, los activos intelectuales son aquellos elementos basados en conocimiento, con los cuales la Compañía propietaria producirá una corriente futura de beneficios para la Compañía. Esto puede incluir tecnología, administración y procesos de consultoría, lo mismo que la extensión hacia la propiedad intelectual patentada".

¡Verdad que el tema es interesante! También es verdad que en el Perú aún no se realizan con fervor profesional estos estudios y son pocos los contadores públicos que transitan por estos nuevos canales de los avances de la contabilidad. 
En la XXIII Conferencia Interamericana de Contabilidad, efectuada en agosto de 1999 en Puerto Rico, se trató en el Área 1. INVESTIGACIÓN CONTABLE dos interesantes temas:

Grupo 1.1 - Nuevos Modelos de Informes Financieros

Grupo 1.2 - Armonización de Principios de Contabilidad

En el Grupo 1.1 - Nuevos Modelos de Informes Financieros se presentaron excelentes trabajos nacionales interamericanos que están a disposición de docentes y alumnos de la Facultad; por cuanto dos profesores que participamos en este importante evento obtuvimos dos juegos de todos los trabajos presentados; un juego de dos tomos está en la Biblioteca de la Facultad, en el tercer piso; y el otro juego está en la principiante biblioteca de la Unidad de Postgrado en el cuarto piso.

$\mathrm{Al}$ respecto, sólo vamos a presentar la siguiente parte del trabajo nacional interamericano titulado "Un Modelo Financiero Proyectado para Usuarios que no se Encuentran en la Posición de Exigir a una Empresa un Informe que Satisfaga sus Necesidades Específicas", mostrado en las páginas 58 y 59 del Tomo de Trabajos Nacionales que dice:

\section{“ 4. 2 El Valor intangible no contabilizado - valor llave que posee la empresa}

Se ha cuestionado a la contabilidad por su incapacidad para reflejar el valor probable de los activos intangibles. Entre las principales cuestiones que se recriminan se encuentran los casos donde no se registran los nuevos desarrollos tecnológicos producidos por la entidad; las capacidades y habilidades de los miembros de la organización aplicadas al negocio; la clientela cautiva que posee; la tenencia de marcas y patentes de invención que fueron incorporadas por su valor de inscripción, en tanto, su posible valor en la de realización supera varias veces su costo; la plusvalía mercantil, etc.

En este tema, la doctrina contable, en general, ha sido terminante y las normas internacionales de contabilidad rechazan la posibilidad de incorporar el valor de intangibles autogenerados por la empresa en marcha.

En tanto, los principios generalmente aceptados de EE.UU. también rechazan el registro de aquellos intangibles que no provengan del sacrificio realizado por su adquisición.

No es posible dejar de señalar que la norma americana establece la necesidad de fijar como límite el valor razonable de mercado, siendo este indicador una unidad de medida poco precisa, cuya verificación exige observar el desarrollo futuro del negocio.

Es acertada la posición que impide reconocer el valor de los intangibles autogenerados. Por otra parte, los estados contables proyectados están en condiciones de recoger mejor los resultados que se producen por la explotación de estos activos, cuando existan evidencias razonables de su existencia".-

Del trabajo nacional interamericano titulado "Un Modelo de Informes Financieros Adaptado a las Necesidades de Información en una Economía Globalizada: Aprendiendo de las Experiencias de la Contabilidad Gerencial", se muestra también 
una parte, de las páginas 71 y 72 , que textualmente dice:

\section{"Forma y contenido de los Informes Financieros}

Va a ser difícil romper con los esquemas tradicionales de la contabilidad. Los estados financieros que se acostumbra presentar, y los elementos que históricamente han sido parte de dichos estados, están muy arraigados en las mentes de los contadores. Por décadas se nos ha enseñado que hay unos informes para uso externo, los cuales siguen una estructura rígida basada en los principios de contabilidad generalmente aceptados. Cualquier información que se desvíe de esa estructura sólo puede usarse para fines internos. Se nos dice que la contabilidad gerencial es para ayudar a la gerencia a tomar decisiones mientras que la contabilidad financiera es para preparar informes dirigidos a los usuarios externos. Cabe entonces preguntarse, ¿Para que quieren los usuarios externos esta información? ¿No es acaso para tomar decisiones?

Es importante, por tanto, hacer la reingeniería necesaria para desarrollar informes financieros que permitan al usuario evaluar la posición competitiva de la empresa a la luz de los factores mencionados. Esto requiere incorporar a los informes financieros nuevos tipos de activos $y$ obligaciones, particularmente los activos intangibles mencionados anteriormente, nuevas formas de presentar los cambios en los mismos y su efecto en la competitividad de la empresa. Es imprescindible, como señala Jenkins, que los usuarios se involucren más en los procesos de establecer normas de contabilidad, las cuales son las que determinan el contenido y la forma de los informes. Esta interacción continua entre los usuarios y los organismos a cargo de establecer las normas de contabilidad es la que promoverá la reingeniería y mantendrá la pertinencia de los informes financieros".

Y ahora, hablemos de la NIC 38. ACTIVOS INTANGIBLES, publicada en setiembre de 1998; al respecto, el CP. Samuel Alberto Mantilla B. en su libro ya mencionado en la parte inicial de este artículo dice lo siguiente:

"La importancia de los activos intangibles es tal que ha llevado a la emisión de una nueva norma internacional de contabilidad (NIC. 38) para el tratamiento de ese tema y de manera especial su reconocimiento, medición y revelación en estados financieros. En el estudio: "Medición y Administración del Capital Intelectual: Una Introducción", se plantean algunas diferencias en relación con ello dado que avanza en la dirección de las prácticas de contabilidad gerencial modernas, las cuales se consideran más apropiadas como herramientas de información para la administración del conocimiento.

Todavía no existe consenso respecto de qué constituye activo de conocimiento. Ello se ve claro en las diferencias que se encuentran en la NIC. 38 y el estudio indicado en el párrafo anterior. El problema principal radica en la volatilidad del conocimiento, frente a lo cual la NIC. 38 tiene bastante cautela: no es posible reconocer un activo en estados financieros (que deberán ser auditables) y que luego tal conocimiento desaparezca sin más y no sea posible retirarlo de dichos 
estados. Es un asunto netamente contable pero de consecuencias muy diversas".

La NIC. 38 - Activos Intangibles, consta de 123 párrafos de gran importancia para el desarrollo de los temas tratados en el presente artículo; reemplaza a la NIC. 4. Contabilización de la Depreciación y la NIC. 9. Costos de Investigación y Desarrollo. En su Introducción dice: "La NIC 38 prescribe la contabilidad y revelación de activos intangibles que no son tratados específicamente en otras NIC's".

Pero, también el Dr. Jorge Tua Pereda, catedrático de la Universidad Autónoma de Madrid - España, en su conferencia titulada: "Normas Internacionales en Contaduría y Auditoría Ambiental", escuchada por más de 1000 contadores públicos en el Seminario Interamericano de Contabilidad realizado en agosto del 2000 , ha planteado interesantes temas sobre la contabilidad ambiental y su derivación hacia una "Responsabilidad Social" que determina el planteamiento de la "CONTABILIDAD SOCIAL", una nueva disciplina que nos falta conocer con más profundidad.

Por todo lo expuesto, se tienen varios paradigmas de utilidad para los contadores públicos en general; así como a los docentes y alumnos de la Facultad de Ciencias Contables de la UNMSM, para mantenernos, como siempre, en el liderazgo de la investigación científica contable, en el desarrollo de mayores conocimientos de la contabilidad para preparar mejores profesionales que servirán a la sociedad peruana; y en la vanguardia de más de 70 facultades que existen en la universidad peruana para formar Contadores Públicos. 